\begin{tabular}{c} 
Brazilian Journal \\
of Chemical \\
Engineering \\
\hline
\end{tabular}

ISSN 0104-6632

Printed in Brazil

www.abeq.org.br/bjche

Vol. 29, No. 03, pp. 549 - 558, July - September, 2012

\title{
INTRODUCING A NEW FORMULA BASED ON AN ARTIFICIAL NEURAL NETWORK FOR PREDICTION OF DROPLET SIZE IN VENTURI SCRUBBERS
}

\author{
A. Sharifi and A. Mohebbi ${ }^{*}$ \\ Department of Chemical Engineering, College of Engineering, \\ Shahid Bahonar University of Kerman, Kerman, Iran. \\ E-mail: amohebbi2002@yahoo.com; amohebbi@mail.uk.ac.ir \\ (Submitted: September 3, 2011 ; Revised: January 2, 2012 ; Accepted: February 3, 2012)
}

\begin{abstract}
Droplet size is a fundamental parameter for Venturi scrubber performance. For many years, the correlations proposed by Nukiyama and Tanasawa (1938) and Boll et al. (1974) were used for calculating mean droplet size in Venturi scrubbers with limited operating parameters. This study proposes an alternative approach on the basis of artificial neural networks (ANNs) to determine the mean droplet size in Venturi scrubbers, in a wide range of operating parameters. Experimental data were used to design the ANNs. A neural network was trained based on the liquid to gas ratio $(\mathrm{L} / \mathrm{G})$ and throat gas velocity $\left(\mathrm{V}_{\mathrm{gth}}\right)$, as input parameters, and the Sauter mean diameter $\left(\mathrm{D}_{32}\right)$ as the desired parameter. The back-propagation learning algorithms were used in the network and the best approach was found. A new formula for the prediction of $\mathrm{D}_{32}$ using the weights of the network was then generated. This formula predicts mean droplet size in Venturi scrubbers more accurately than the correlations of Boll et al. (1974) and Nukiyama and Tanasawa (1938). The Average Absolute Percent Deviation (AAPD) of our formula and the Boll et al. and Nukiyama and Tanasawa correlations for the full ranges of experimental data are $26.04 \%, 40.19 \%$ and $32.99 \%$, respectively.

Keywords: Venturi scrubber; Droplet size; Artificial neural networks (ANNs); Boll correlation; NT correlation.
\end{abstract}

\section{INTRODUCTION}

Venturi scrubbers are used to collect particulate or gaseous pollutants from gas streams. Their main practical advantages are the removal of both tiny particles and toxic gaseous components. Liquid is atomized to very small droplets and these droplets remove pollutants from the gas by impaction and interception mechanisms. The collection efficiency is a complex function of many parameters, including droplet size and concentration distribution, liquid to gas ratio, jet penetration, and liquid film fraction. One of the most important parameters for performance, calculations and modeling of Venturi scrubbers is droplet size.

Two correlations have been used to estimate the mean droplet size in Venturi scrubbers: one is the classic correlation proposed by Nukiyama and Tanasawa (1938) and another is the correlation of Boll et al. (1974). Several models for Venturi scrubbers have used the correlation developed by Nukiyama and Tanasawa (1938) for pneumatic atomizers to specify droplet size. In this correlation, the gas velocity is considered to be high $(73-230 \mathrm{~m} / \mathrm{s})$ and the liquid to gas ratio as low as $0.08-1.0 \mathrm{~L} / \mathrm{m}^{3}$. The correlation is given as:

*To whom correspondence should be addressed 


$$
\begin{array}{r}
\mathrm{D}_{32}=\frac{0.585}{v_{\mathrm{r}}} \sqrt{\frac{\sigma}{\rho_{1}}}+1.683 \times 10^{-3} \\
\left(\frac{\mu}{\sqrt{\sigma \rho_{1}}}\right)^{0.45}\left(\frac{1000 \mathrm{Q}_{1}}{\mathrm{Q}_{\mathrm{g}}}\right)^{1.5}
\end{array}
$$

Parker and Cheong (1973), who injected water as a film, measured the droplet size downstream from their Venturi scrubber. They indicated that the water entraining produces a large number of small droplets in the size range of $10-20 \mu \mathrm{m}$ in diameter, which is smaller than the sizes predicted by the equation of Nukiyama and Tanasawa (1938). These are atomized by aerodynamic forces in the throat.

Boll et al. (1974) reported mean drop size measurements in a commercial-scale Venturi scrubber using practical ranges of operating conditions. They varied the liquid to gas ratios from 0.6 to $2.4 \mathrm{~L} / \mathrm{m}^{3}$ and assumed that the droplets were created immediately when injection is started. As a result of their experiments with spray injection, they proposed the following correlation for an air/water system:

$$
\mathrm{D}_{32}=\frac{4.22 \times 10^{-2}+5.77 \times 10^{-3}\left(\frac{1000 \mathrm{Q}_{1}}{\mathrm{Q}_{\mathrm{g}}}\right)^{1.922}}{\mathrm{~V}_{\mathrm{gth}}^{1.602}}
$$

Leith et al. (1985) presented data for droplet size in a Venturi scrubber. They used a constant throat gas velocity of $72 \mathrm{~m} / \mathrm{s}$, and a liquid-to-gas ratio of $1.3 \mathrm{~L} / \mathrm{m}^{3}$. They reported Sauter mean diameters in the range of 200-500 $\mu \mathrm{m}$.

Alonso et al. (2001) reported new data taken in a cylindrical laboratory-scale Venturi, using the Fraunhofer diffraction technique for size measurements. The gas velocities and liquid to gas ratios were varied from 50 to $90 \mathrm{~m} / \mathrm{s}$ and 0.5 to $2.0 \mathrm{~L} / \mathrm{m}^{3}$, respectively. The results were used to identify the most suitable correlations to describe the droplet size and the authors concluded that the Sauter mean diameter can be properly correlated with the equation of Boll et al. (1974).

Costa et al. (2004) using the same technique as Alonso et al. (2001), measured the droplet size as a function of gas velocity ( 58.3 to $74.9 \mathrm{~m} / \mathrm{s}$ ), liquid to gas ratio $\left(0.07\right.$ to $\left.0.27 \mathrm{~L} / \mathrm{m}^{3}\right)$, and distance from liquid injection point (64 to $173 \mathrm{~mm}$ ) in a rectangular-scale Venturi and concluded that neither the correlation of Nukiyama and Tanasawa (1938) nor that of Boll et al. (1974) gives satisfactorily predictions of the experimental data.
Silva et al. (2009) obtained new data on droplet size, which was measured by laser diffraction. Two different methods of liquid injection were addressed and liquid flow rates extended into a range of low liquid loading $(0.013-0.075 \mathrm{~kg} / \mathrm{s})$ and the maximum velocity at the throat was $70 \mathrm{~m} / \mathrm{s}$. They concluded that, when liquid is injected as spray, droplet size is mostly controlled by the nozzle characteristics and the interaction with the gas in the upstream in the Venturi.

Guerra et al. (2009) measured the effect of multiple jet liquid injection on the formation and distribution of droplets in a Venturi scrubber. They considered different liquid injection configurations with gas velocity and liquid flow rates as parameters. They also studied the evolution of the droplet size along the axis of their Venturi scrubber.

Several data infilling techniques such as artificial neural networks (ANNs), regression methods and stochastic models have been commonly used, but the artificial neural networks (ANNs) technique can be used to express a non-linear mapping between variables with no prior assumptions on the variables and this technique can cope with missing data (French et al., 1992). Nasseh et al. (2007, 2009) designed a new model based on artificial neural networks to predict the pressure drop in Venturi scrubbers. They used several sets of experimental data from Venturi scrubbers to design an ANN. Their results showed that ANNs give a better performance for predicting the pressure drop than annular two-phase flow models. Taheri et al. (2008) used the same procedure to predict the collection efficiency in Venturi scrubbers, but there is no study on the application of ANNs to predict the droplet size in Venturi scrubbers in literature. The two correlations of Nukiyama and Tanasawa (1938) and Boll et al. (1974) are widely used for prediction of the mean droplet size in Venturi scrubbers. However, the range of application of these correlations is restricted to the range of experimental data of liquid to gas ratio and throat gas velocity used for deriving them. Therefore, more research on the application of new techniques such as ANNs to predict droplet size in Venturi scrubbers over a wider range of experimental data is needed.

The purpose of this study was to determine the Sauter mean diameter of droplets based on artificial neural networks in Venturi scrubbers and to introduce a new formula using the weights of the network. The accuracy of this new formula based on ANNs was investigated and the results were compared to the correlations of Nukiyama and Tanasawa (1938) and Boll et al. (1974). 


\section{ARTIFICIAL NEURAL NETWORKS}

Neural networks are powerful tools for the approximation of unknown nonlinear functions and have gained applications in a variety of fields (Mousavi Dehghani et al., 2008). ANNs are collections of small individual interconnected processing units. Information is passed between these units along interconnections. They learn the relationship between the input and the output. The network usually consists of an input layer, some hidden layers, and an output layer (Kalogirou, 2000). Each input is multiplied by a connection weight. In the simplest case, the products and biases are simply summed, then transformed through a transfer function to generate a result, and finally the output is obtained (Sözen et al., 2005). An important stage of a neural network is the training step. The most famous training algorithm is the back-propagation algorithm (BP). Back-propagation-type neural networks have an input, an output and, in most of the applications, have one hidden layer.

Back-propagation training algorithms of gradient descent and gradient descent with momentum are often too slow for practical problems because they require small learning rates for stable learning. Faster algorithms such as conjugate gradient, quasiNewton, and Levenberg-Marquardt (LM) use standard numerical optimization techniques. The LM method is in fact an approximation of Newton's method (Sözen et al., 2009).

The error during the learning is called the Mean Squared Error (MSE) and is defined as:

$$
\mathrm{MSE}=\frac{\sum_{\mathrm{i}=1}^{\mathrm{n}}\left(\mathrm{O}_{\mathrm{i}}-\mathrm{T}_{\mathrm{i}}\right)^{2}}{\mathrm{n}}
$$

in which, $\mathrm{O}_{\mathrm{i}}$ is the desired output for the training data or cross-validation data $i, T_{i}$ is the network output for the training data or cross-validation data $i$, and $n$ is the number of data in the training data set or the cross-validation data set.

The effectiveness of various methods of estimating the relative importance of input parameters in ANN models has been reviewed (Gevrey et al., 2003; Olden et al., 2004). Olden et al. (2004) compared a number of methods to determine the importance of parameters in ANNs using a simulation-based approach. Their proposed connection weight method outperforms all other methods in determining relative parameter importance in ANNs.

The connection weight method sums the product of the weight of the connection from input neuron to the hidden neurons with the weight of the connection from the hidden neurons to the output neurons for all input parameters. The importance of a parameter is great if the sum of connection weights for that parameter is large. The relative importance of an input parameter $\mathrm{i}$ is determined using the following Eq. (4), (Olden et al., 2004):

$$
\operatorname{Imp}(\mathrm{i})=\sum_{\mathrm{i}=1}^{\mathrm{n}}\left(\mathrm{CW}_{\mathrm{ih}(\mathrm{x})} \mathrm{CW}_{\mathrm{ho}(\mathrm{x})}\right.
$$

where $\operatorname{Imp}(\mathrm{i})$ is the relative importance of parameter $\mathrm{i}, \mathrm{n}$ is the total number of hidden neurons, $\mathrm{x}$ is the index number of the hidden neuron, $\mathrm{CW}_{\mathrm{in}(\mathrm{x})}$ is the connectivity weight between input parameter $\mathrm{i}$ and the hidden neuron $\mathrm{x}$ and $\mathrm{CW}_{\mathrm{ho}(\mathrm{x})}$ is the connectivity weight between the hidden neuron $\mathrm{x}$ and the output neuron. In this study, Eq. (4) was used to determine the importance of parameters in our ANN.

\section{ANN DETAILS AND DATA PREPARATION}

This study applied ANNs to calculate the Sauter mean diameter in Venturi scrubbers. Experimental data were extracted from several papers (Boll et al., 1974; Alonso et al., 2001; Costa et al., 2004; Guerra et al., 2009) with different variables and methods of liquid injection. These data were used for training the network; their ranges are summarized in Table 1. The input vectors for the network were liquid to gas ratio $(\mathrm{L} / \mathrm{G})$ and throat gas velocity $\left(\mathrm{V}_{\mathrm{gth}}\right)$, whereas the output vector was the Sauter mean diameter $\left(\mathrm{D}_{32}\right)$ in the Venturi scrubbers. The design of the ANNs is shown in Fig. 1.

Table 1: The ranges of experimental data used for training network.

\begin{tabular}{|l|c|c|c|}
\hline \multicolumn{1}{|c|}{$\mathbf{V}_{\text {gth }}(\mathbf{m} / \mathbf{s})$} & $\mathbf{L} / \mathbf{G}\left(\mathbf{m}^{\mathbf{3}} / \mathbf{1 0 0 0} \mathbf{~ m}^{\mathbf{3}}\right)$ & $\mathbf{D}_{\mathbf{3 2}}(\boldsymbol{\mu \mathbf { m }})$ & Reference \\
\hline $30.48,45.72,60.96,91.44$ & $0.6-2.4$ & $40-560$ & Boll et al. $(1974)$ \\
$50,70,90$ & $0.5-2$ & $30-140$ & Alonso et al. $(2001)$ \\
$58.3,66.6,74.9$ & $0.07,0.17,0.27$ & $28.4-170.8$ & Costa et al. $(2004)$ \\
$59,64,69,74$ & $0.07-0.3$ & $22.5-143$ & Guerra et al. $(2009)$ \\
\hline
\end{tabular}




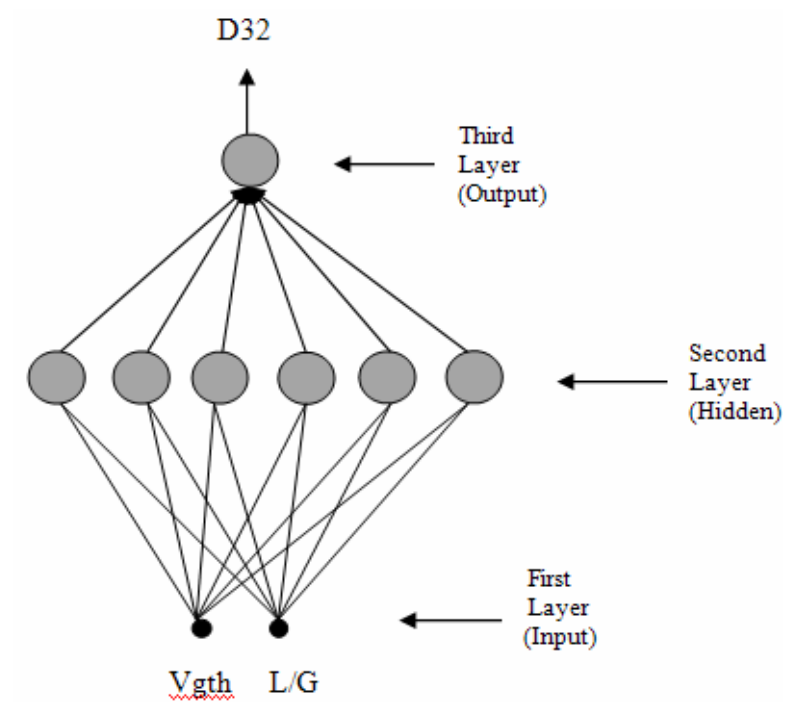

Figure 1: The design of ANNs.

The ANN contains three layers and used the feedforward back-propagation algorithm to train the input data. The learning algorithm employed in this study was LM, which is a faster algorithm than other algorithms. Tan-Sigmoid (Tansig) and Pureline transfer functions were used in the hidden and output layers, respectively. A computer program was developed under MATLAB software (Matlab User's Guide, Copyright, 2008). In the training, six neurons were applied in a hidden layer to obtain more accurate outputs. The neurons in the hidden layer perform two tasks: they sum the weighted inputs connected to them and pass the resulting summations through a non-linear activation function to the output neuron or adjacent neurons of the corresponding hidden layer.
The correlation coefficient between the dependent and independent parameters may be improved by normalizing the distribution data. Inputs and outputs are normalized in the range of $(-1,1)$ as follows:

$\mathrm{X}_{\mathrm{N}}=2 \times\left[\frac{\mathrm{X}_{\mathrm{R}}-\mathrm{X}_{\min }}{\mathrm{X}_{\max }-\mathrm{X}_{\min }}\right]-1$

where $X_{R}$ is the original data; $X_{\min }$ is the minimum of $\mathrm{X}_{\mathrm{R}} ; \mathrm{X}_{\max }$ is the maximum of $\mathrm{X}_{\mathrm{R}}$ and $\mathrm{X}_{\mathrm{N}}$ is the result of normalization. The input and target vectors entered the network normalized and the network was trained with these vectors. To train the ANN, no more patterns are necessary. The aim of ANN is to estimate the internal values accurately according to statistical values such as: Linear Correlation Coefficient (R), Mean Squared Error (MSE); the training can be achieved with sufficient data. When the network training was successfully finished, the network was tested using the test data.

\section{RESULTS AND DISCUSSION}

In this study, a set of 652 experimental data points (Boll et al., 1974; Alonso et al., 2001; Costa et al., 2004; Guerra et al., 2009) for droplet diameter was used to design the ANNs. Moreover, $70 \%$ of the data (i.e., 456 data) was used for training process, $15 \%$ (i.e., 98 data) for validation and the rest $15 \%$ (i.e., 98 data) for testing. The best approach, which had minimum error, was performed by the LM algorithm with 6 neurons in the hidden layer. Performance of the network in training, validation and test is illustrated in Figs. 2-4.

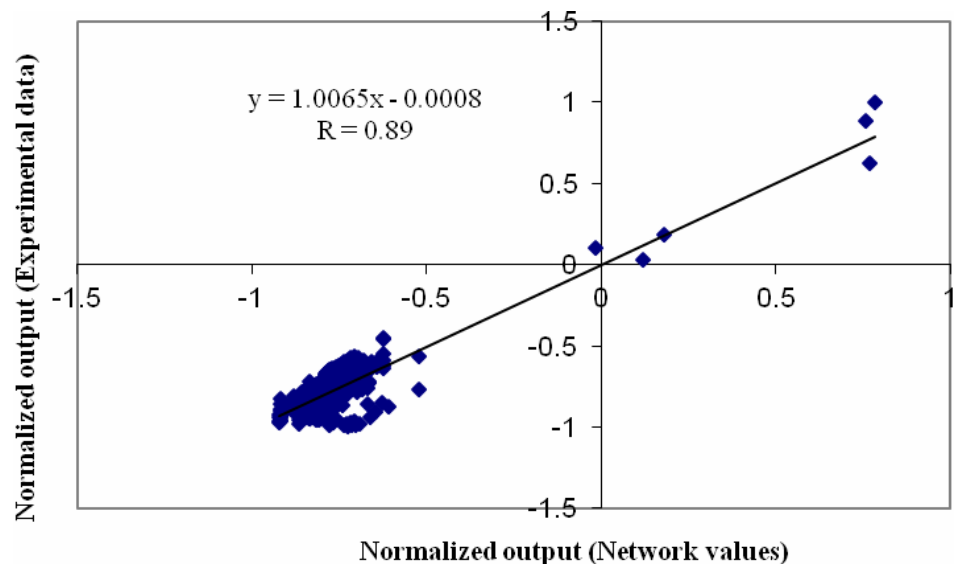

Figure 2: Performance of the network for the training data set. 


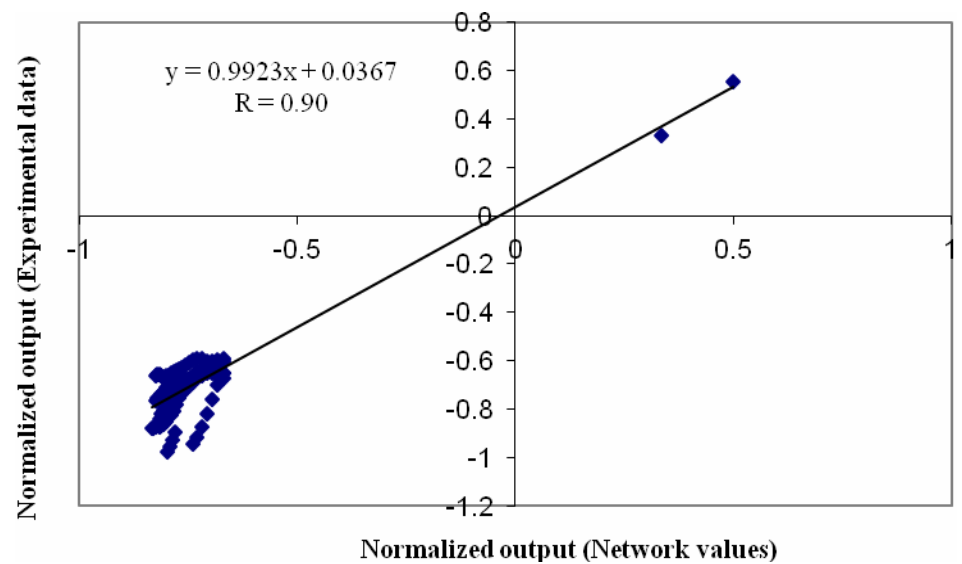

Figure 3: Performance of the network for the validation data set.

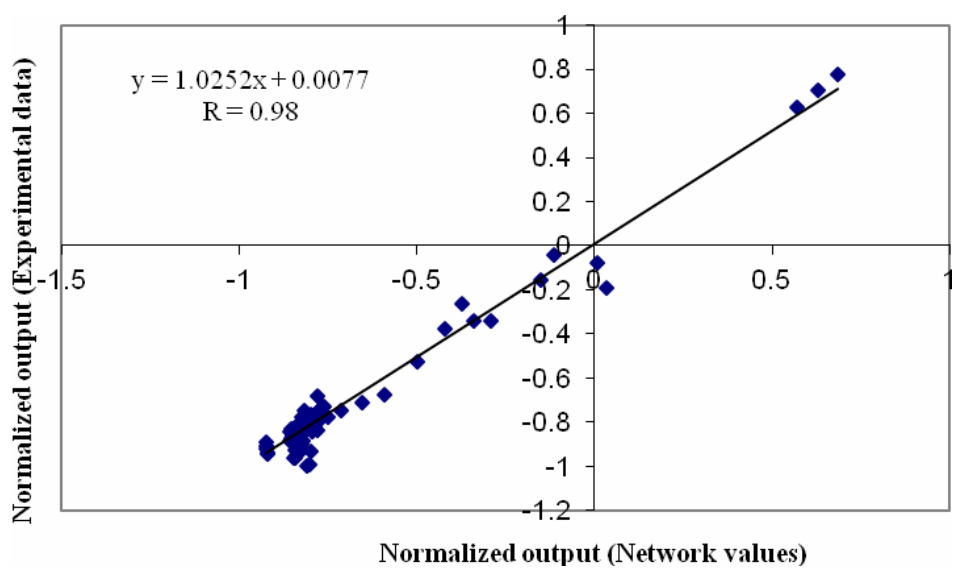

Figure 4: Performance of the network for the testing data set.

Table 2 gives the ANN performance in terms of: mean squared error (MSE), normalized mean squared error (NMSE), mean absolute error (MAE), minimum absolute error and maximum absolute error and the linear correlation coefficient (R) between the experimental data and neural network outputs.

A plot of the training, validation, and testing errors; is shown in Fig. 5. The result is reasonable because the test set error and the validation set error have similar characteristics and it does not appear that any significant overfitting has occurred. The training was stopped after 15 iterations, where the best validation performance occurs. This figure also shows the mean square error of the network starting at a large value and decreasing to a smaller value. In other words, it shows that the network is learning.

According to the above network training, a formula for mean droplet diameter prediction was developed by using the algorithm's weights. The Tan-Sigmoid (Tansig) transfer function used in the hidden layer is given in Eq. (6):

$$
\begin{aligned}
& \mathrm{F}_{\mathrm{i}}=\frac{2}{\left(1+\exp \left(-2 \mathrm{E}_{\mathrm{i}}\right)\right)}-1 \\
& \mathrm{i}=1: 6
\end{aligned}
$$

where $E_{i}$ values are given in Table 3 .

Therefore, Eqs. (6) and (7) permitted mean droplet diameter prediction.

$$
\begin{aligned}
\mathrm{D}_{32}= & -0.0461 \mathrm{~F}_{1}-0.8102 \mathrm{~F}_{2}+0.3191 \mathrm{~F}_{3} \\
& -0.1103 \mathrm{~F}_{4}+0.2402 \mathrm{~F}_{5}+0.7575 \mathrm{~F}_{6}+0.8799
\end{aligned}
$$

The results are shown in Fig. 6 for $\mathrm{D}_{32}$ prediction using this formula based on the algorithm's weights. This formula gives a very accurate representation, indicated by the statistical values such as $\mathrm{R}$ and MSE, over the full range of operating conditions. The mean square error and Linear Correlation Coefficient for the new proposed model are 0.0065 and 0.9210 , respectively. 
Table 2: Performance of ANN model for test data set.

\begin{tabular}{|l|c|}
\hline Performance & Best Network \\
\hline MSE & 0.003417 \\
NMSE & 0.034836 \\
MAE & 0.039539 \\
Min absolute error & 0.000908 \\
Max absolute error & 0.225085 \\
R & 0.98329 \\
\hline
\end{tabular}

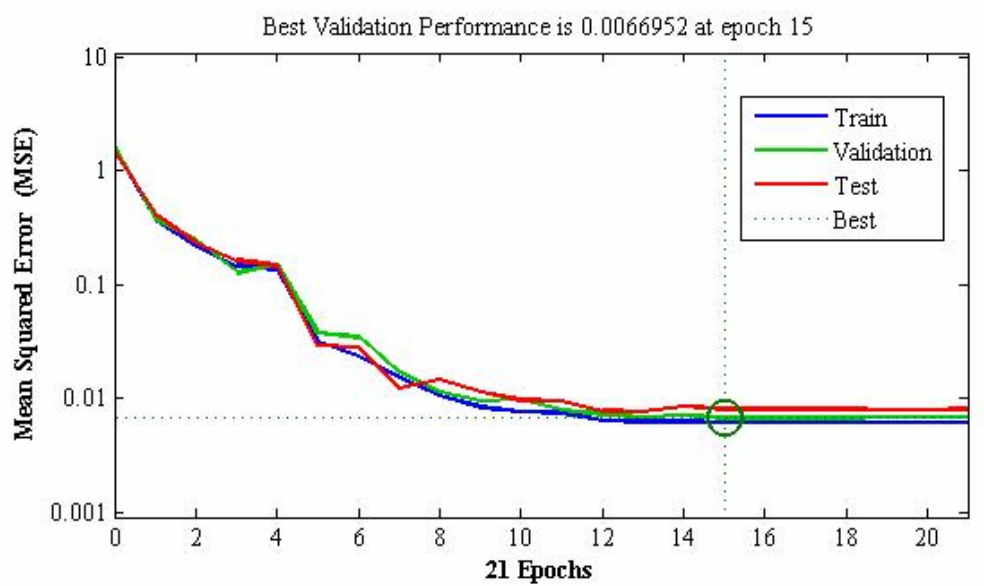

Figure 5: Performance of the network at different epochs.

Table 3: Weight values obtained by the LM algorithm with 6 neurons.

\begin{tabular}{|c|c|c|c|}
\hline \multicolumn{4}{|c|}{$\mathbf{E}_{\mathbf{i}}=\mathbf{W}_{\mathbf{i} 1} \times \mathbf{V}_{\mathbf{g t h}}+\mathbf{W}_{\mathbf{i} 2} \times \frac{\mathbf{L}}{\mathbf{G}}+\mathbf{b}_{\mathbf{i}}$} \\
\hline $\mathbf{i}$ & $\mathbf{W}_{\mathbf{i} 1}$ & $\mathbf{W}_{\mathbf{i} 2}$ & $\mathbf{b}_{\mathbf{i}}$ \\
\hline 1 & 1.0101 & 5.1757 & 3.7899 \\
2 & 1.8249 & 5.5311 & 6.3559 \\
3 & 8.3765 & 2.1827 & 0.6230 \\
4 & 1.0427 & -5.1016 & 1.9217 \\
5 & 10.5198 & 0.6973 & 1.7401 \\
6 & -19.1645 & 0.5104 & -9.3669 \\
\hline
\end{tabular}

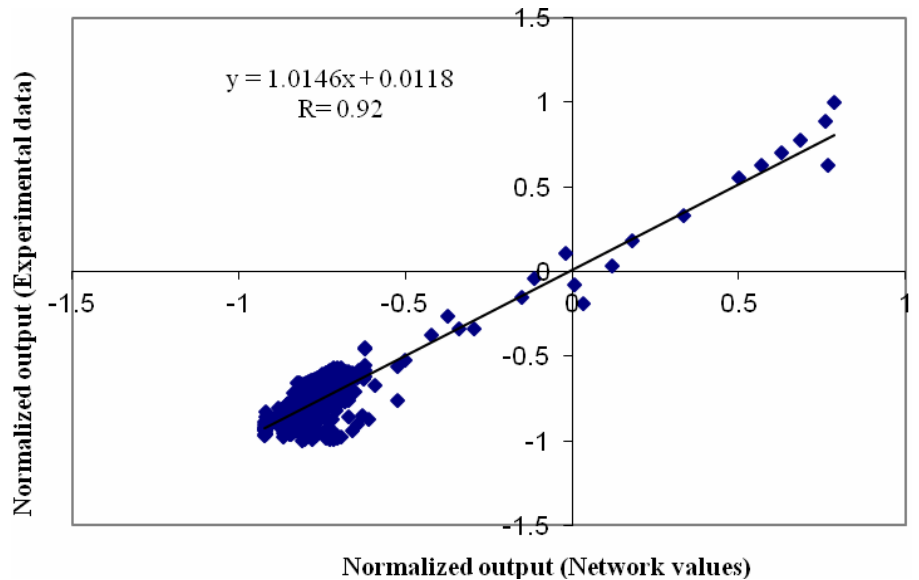

Figure 6: Performance of the network output versus experimental data in the output. 
In Figure 7 the experimental data for mean droplet diameters $\left(\mathrm{D}_{32}\right)$ are compared with those calculated by this new formula, Boll's correlation and the Nukiyama and Tanasawa (N.T)'s correlation for the same liquid to gas ratio $(\mathrm{L} / \mathrm{G})$ and throat gas velocity $\left(\mathrm{V}_{\text {gth }}\right)$. It can be seen that there is an excellent agreement between the results of our formula and the experimental data. From this figure, the Average Absolute Percent Deviation (AAPD) parameter for the results of our formula and the Boll and N.T correlations are $4.25 \%, 51.93 \%$ and $42.6 \%$, respectively according to the expression:

AAPD $=\frac{1}{\mathrm{~N}} \sum_{\mathrm{i}=1}^{\mathrm{N}}\left|\left(\frac{\mathrm{D}_{32 \exp }-\mathrm{D}_{32 \mathrm{cal}}}{\mathrm{D}_{32 \exp }}\right)_{\mathrm{i}}\right| \times 100$
Moreover, the AAPD for the full ranges of experimental data used in this study for our formula and the Boll and N.T correlations was $26.04 \%$, $40.19 \%$ and $32.99 \%$, respectively. The ranges of application of our formula and the Boll and N.T correlations are given in Table 4.

Figures 8, 9, 10 and 11 compare the results of this new formula for predicting mean droplet size with experimental data and those predicted by the Boll et al. (1974) and N.T (1938) correlations for different liquid to gas ratios and throat gas velocities. As one can see from these figures, there is an excellent agreement between the results of our formula and the experimental data.

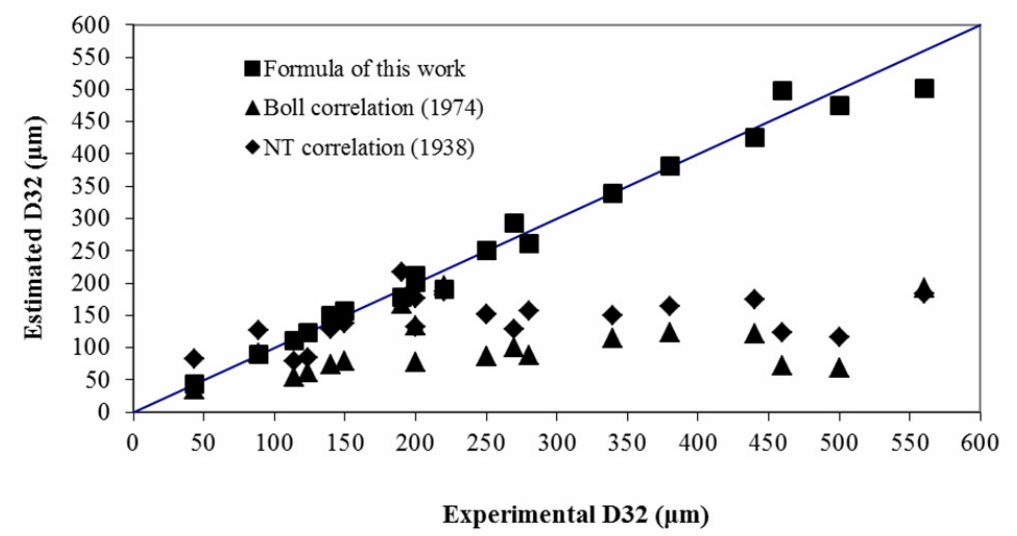

Figure 7: The comparison of different models with the results of the ANN

Table 4: The ranges of application of correlation for predicting mean droplet size.

\begin{tabular}{|l|c|l|}
\hline & \multicolumn{2}{|c|}{ Ranges of application } \\
\hline \multicolumn{1}{|c|}{ Correlation } & $\mathbf{L} / \mathbf{G ~} \mathbf{( m}^{\left.\mathbf{3} / \mathbf{1 0 0 0} \mathbf{~ m}^{\mathbf{3}}\right)}$ & \multicolumn{1}{c|}{$\mathbf{V}_{\mathbf{g t h}}(\mathbf{m} / \mathbf{s})$} \\
\hline This work & $0.07-2.4$ & $30.48-92$ \\
Boll et al. (1974) & $0.6-2.4$ & $30.48,45.7,60.96,91.44$ \\
Nukiyama and Tanasawa (1938) & $0.08-1.0$ & $73-230$ \\
\hline
\end{tabular}

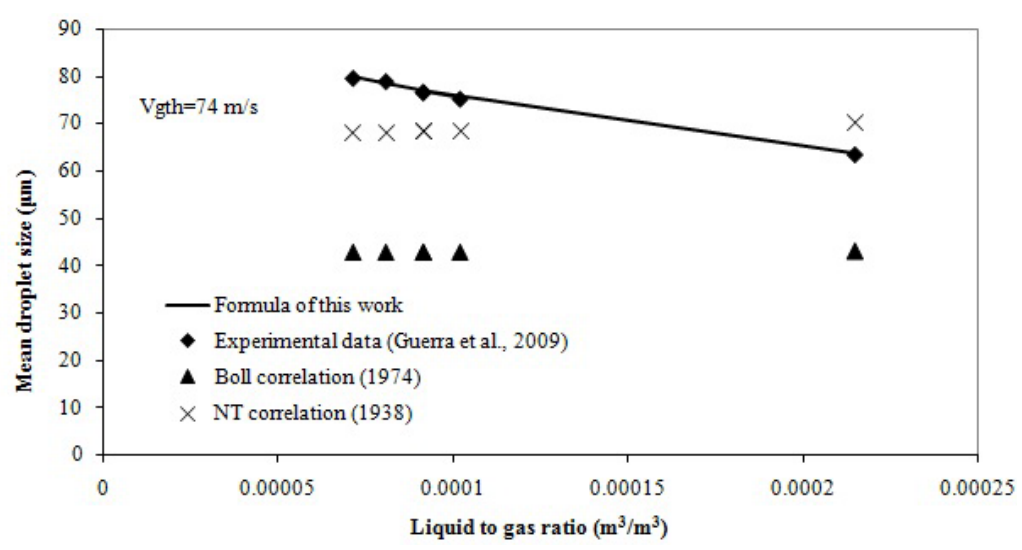

Figure 8: Variation of $D_{32}$ with liquid to gas ratio for $V_{\mathrm{gth}}=74 \mathrm{~m} / \mathrm{s}$. 


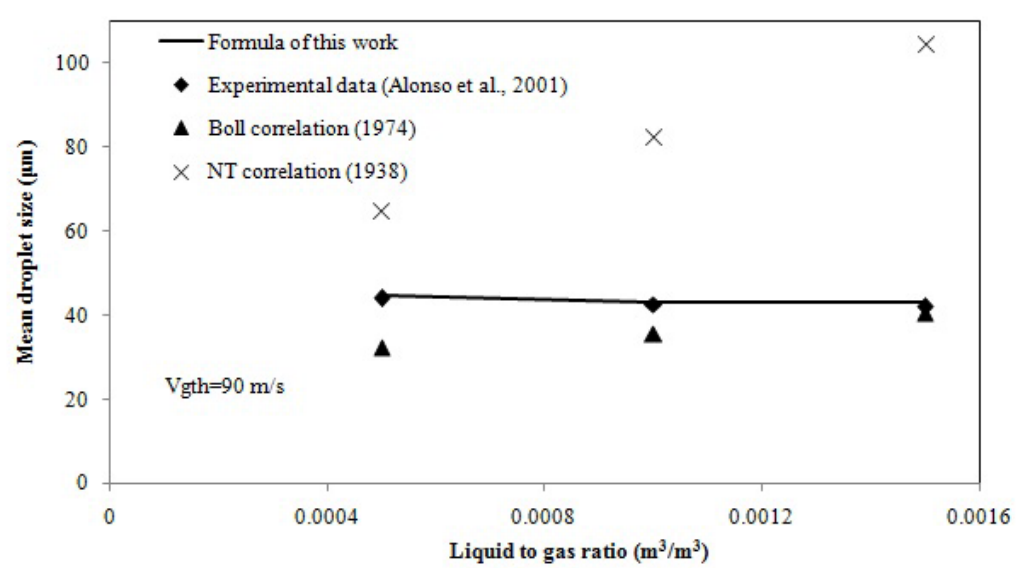

Figure 9: Variation of $D_{32}$ with liquid to gas ratio for $V_{\mathrm{gth}}=90 \mathrm{~m} / \mathrm{s}$.

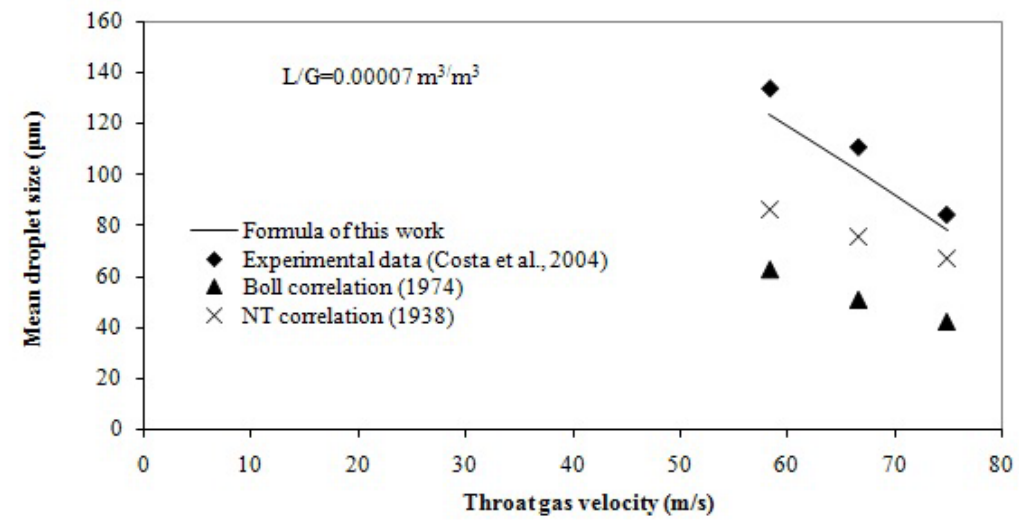

Figure 10: Variation of $D_{32}$ with throat gas velocity for $L / G=0.00007 \mathrm{~m}^{3} / \mathrm{m}^{3}$.

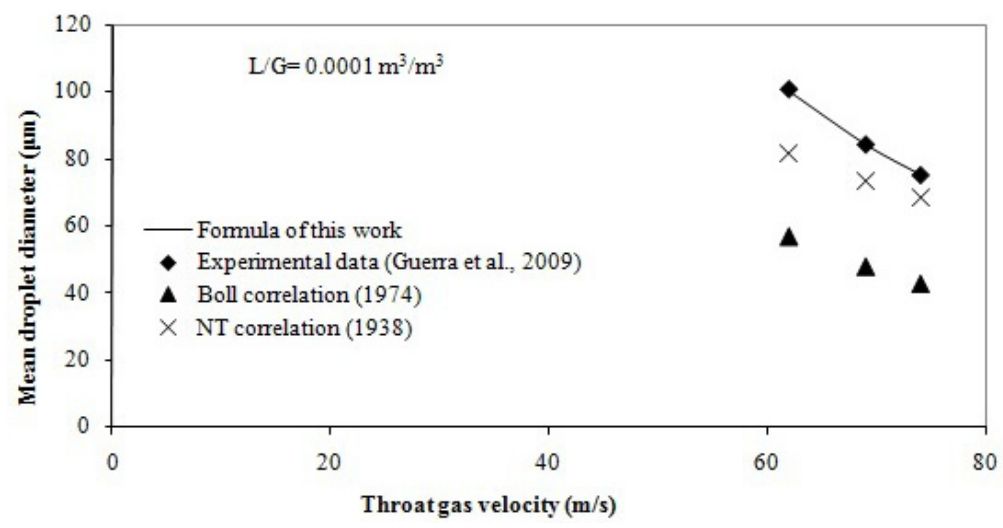

Figure 11: Variation of $D_{32}$ with throat gas velocity for $L / G=0.0001 \mathrm{~m}^{3} / \mathrm{m}^{3}$.

Finally, the relative importance of the input parameters was determined using Eq. (4). The value of the sum of weights (i.e., $\operatorname{Imp(i))~for~input~parameters,~}$ namely the throat gas velocity and the liquid to gas ratio $(\mathrm{L} / \mathrm{G})$ were -16.303 and -2.906 respectively. This shows that the throat gas velocity has a greater influence on the output parameter (i.e., mean droplet size); therefore, the parameter $\mathrm{V}_{\mathrm{gth}}$ significantly contribute to the predictive ability of the ANN model. The larger negative value of $\operatorname{Imp}(i)$ for the throat gas velocity shows that the output parameter is inversely proportional to this parameter. This finding is in accordance with the correlations of Nukiyama and Tanasawa (1938) and Boll et al. (1974). 


\section{CONCLUSIONS}

An ANN based methodology for the calculation of droplet size in Venturi scrubbers was developed and a new formula for predicting mean droplet size was introduced. With the formula obtained, the user may use such results without a system running the relevant ANN software. Also, the connectivity weight method quantified the total of the connection weights from input to output for each parameter and showed that the throat gas velocity is the major factor that influences droplet size in Venturi scrubbers. The liquid to gas ratio plays a minor role. This new empirical formula calculates the droplet size over a wider range of the liquid to gas ratio and throat gas velocity than the correlations of Nukiyama and Tanasawa (1938) and Boll et al. (1974). The comparison of the prediction accuracies of our formula based on the ANN model with the two previous correlations indicated that our formula is more accurate than the mentioned correlations in predicting $\mathrm{D}_{32}$.

\section{NOMENCLATURE}

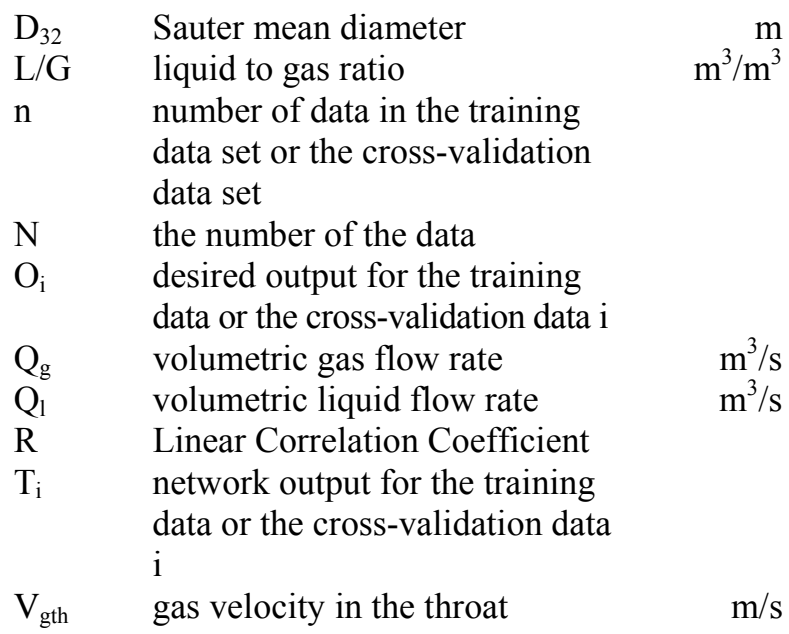

\section{Greek Letters}

$\sigma \quad$ surface tension $\quad \mathrm{N} / \mathrm{m}$

$\mu \quad$ liquid viscosity $\mathrm{kg} / \mathrm{m} . \mathrm{s}$

$\rho_{1} \quad$ liquid density $\mathrm{kg} / \mathrm{m}^{3}$

$v_{\mathrm{r}} \quad$ Relative axial velocity between $\mathrm{m} / \mathrm{s}$ gas and liquid

\section{Subscripts}

L liquid

g gas

$\begin{array}{ll}\text { th } & \text { throat } \\ \text { exp } & \text { experimental } \\ \text { cal } & \text { calculated } \\ \mathrm{r} & \text { relative }\end{array}$

\section{REFERENCES}

Alonso, D. F., Gonçalves, J. A. S., Azzopardi, B. J. and Coury, J. R., Drop size measurements in Venturi scrubbers. Chem. Eng. Sci., 56, p. 4901 (2001).

Boll, R. H., Flairs, L. R., Maurer, P. W. and Thompson, W. L., Mean drop size in a full size Venturi scrubber via transmissometer. J. Air Pollut. Control Assoc., 24, p. 932 (1974).

Costa, M. A. M., Henrique, P. R., Gonçalves, J. A. S. and Coury, J. R., Droplet size in a rectangular Venturi scrubber. Braz. J. Chem. Eng., 21, p. 335 (2004).

French, N., Krajewsky, F. and Cuykendall, R., Rainfall forecasting in space and time using neural network. J. Hydrol., 137, p. 1 (1992).

Gevrey, M., Dimopoulos, I., Lek, S., Review and comparison of methods to study the contribution of variables in artificial neural network models. Ecol. Model., 160, p. 249 (2003).

Guerra, V. G., Gonçalves, J. A. S. and Coury, J. R., Experimental investigation on the effect of liquid injection by multiple orifices in the formation of droplets in a Venturi scrubber. J. Hazard. Mater., 161, p. 351 (2009).

Kalogirou, S. A., Applications of artificial neuralnetworks for energy systems. J. Appl. Energ., 67, p. 17 (2000).

Leith, D., Martin, K. P. and Cooper, D. W., Liquid utilisation in a Venturi scrubber. Filtr. Separat., (May/June), p. 191 (1985).

Matlab User's Guide. The Math Works, Inc., Copyright (2008).

Mousavi Dehghani, S. A., Vafaie Sefti, M., Ameri, A. and Shojai Kaveh, N., Minimum miscibility pressure prediction based on a hybrid neural genetic algorithm. J. Chem. Eng. Res. Des., 86, p. 173 (2008).

Nasseh, S., Mohebbi, A., Jeirani, Z. and Sarrafi, A., Predicting pressure drop in Venturi scrubbers with artificial neural networks. J. Hazard. Mater., 143, p. 144 (2007).

Nasseh, S., Mohebbi, A., Sarrafi, A. and Taheri, M., Estimation of pressure drop in Venturi scrubbers based on annular two-phase flow model, artificial neural networks and genetic algorithm. J. Chem. Eng., 150, p. 131 (2009). 
Nukiyama, S. and Tanasawa, Y., Experiment on atomization of liquid by means of air stream. Trans. Soc. Mech. Eng. Jpn., 4, p. 86 (1938).

Olden, J. D., Joy, M. K., Death, R. G., An accurate comparison of methods for quantifying variable importance in artificial neural networks using simulated data. Ecol. Model., 178, p. 389 (2004).

Parker, G. J. and Cheong, K. C., Air-water tests on a Venturi for entraining liquid films. Int. J. Fluid Mech. Sci., 15, p. 633 (1973).

Silva, A. M., Teixeira, J. C. F. and Teixeira, S. F. C. F., Experiments in large scale Venturi scrubber Part II: Droplet size. Chem. Eng. Process., 48, p. 424 (2009).
Sözen, A., Arcaklioğlu, E., Menlik, T. and Özalp, M., Determination of thermodynamic properties of an alternative refrigerant (R407c) using artificial neural network. J. Expert. Syst. Appl., 36, p. 4346 (2009).

Sözen, A., Arcaklioğlu, E. and Özalp, M., Formulation based on artificial neural network of thermodynamic properties of ozone friendly refrigerant/absorbent couples. J. Appl. Therm. Eng., 25, p. 1808 (2005).

Taheri, M. and Mohebbi, A., Design of artificial neural networks using a genetic algorithm to predict collection efficiency in Venturi scrubbers. J. Hazard. Mater., 157, p. 122 (2008). 